\section{AB0849 1 FATIGUE IN PSORIATIC ARTHRITIS - PREVALENCE AND IMPACT IN DAILY RHEUMATOLOGIC OUTPATIENT CARE}

C. B. Vigener-Buxel ${ }^{1}$, H. E. Langer ${ }^{2}$, S. G. Werner ${ }^{2}$, R. Chatelain ${ }^{1} .{ }^{1} 1$ Fakultät für Gesundheit der Universität Witten/Herdecke, Evangelisches Krankenhaus Düsseldorf, Department of Dermatology, Düsseldorf, Germany; ${ }^{2} \mathrm{RHIO}$ (Rheumatology, Immunology, Osteology) and RHIO Research Institute, Düsseldorf, Düsseldorf, Germany

Background: Fatigue is a major problem in various rheumatic diseases. Only a few studies so far have focused on the occurrence of fatigue in psoriatic arthritis (PsA) (1).

Objectives: The aim of this study was to explore the prevalence and impact of fatigue in patients with PsA and its potentially association with disease activity in daily routine rheumatologic care.

Methods: 105 consecutive outpatients with definitive PsA (mean age 62 years, mean disease duration 8 years) were included in this prospective study. Patients received a clinical examination and laboratory tests. Furthermore, following assessments were used: assessment of disease activity (patient (PG) and physician global (PhG), NRS, 0-10), DAS28, CDAl, pain (NRS, 0-10), HAQ, SF-36, fatigue (NRS (0-10) and Chalder Fatigue Scale (CFS; bimodal: 0-3 no fatigue, 4-11 fatigue; Likert scale: 0-3 no fatigue, 4-33 fatigue, 19-33 severe fatigue/ chronic fatigue syndrome) (2).

Results: In the CFS questionnaire 56/105 patients (53\%) were classified as fatigue cases (bimodal score $>4$ ). 22/105 $(21 \%)$ suffered from severe fatigue/ chronic fatigue syndrome (score $>19$, Likert scale). Mean fatigue was 14,9 (CFS, Likert Scale) and 4,5 (NRS). In $n=47$ (45\%) patients fatigue was present $<3$ months, in $22(21 \%)$ patients 3-6 months, whereas in $n=34(32 \%)>6$ months. Intraday fatigue occurred in $75-100 \%$ of full daytime in 20 patients (19\%).

An extensive impairment of the health related quality of life has been shown in all categories of $S F 36(P F=46 ; R P=52, B P=42, G H=53, V I=45, S F=74, R E=51$, $\mathrm{MH}=68$ ). Fatigue strongly correlated with 6 dimensions of $\mathrm{SF} 36$ : $\mathrm{RP} r=-0,61, \mathrm{BP}$ $r=-0,73, \mathrm{GH}=-0,66, \mathrm{VI} r=-0,79, \mathrm{SF} r=-0,54, \mathrm{MH} r=-0,59$

On average disease activity was low (mean DAS28 $=2,5$ ) with a range from 0,5 to 7,8 .

Fatigue strongly correlated with the $P G(r=0,72)$ as well as with DAS28 $(r=0,49)$, CDAI $(r=0,57)$, pain $(r=0,71)$, tender joint count $(r=0,41)$ and $H A Q$ $(r=0.57)$. The $P h G$ showed only a poor correlation with fatigue $(r=0,29)$. There was no correlation with ESR $(r=-0,01), \operatorname{CRP}(r=0,14)$ and swollen joint count $(r=0,17)$.

$63 / 105(60 \%)$ patients were in DAS28 remission (DAS28 < 2.6) but 24/63 $(38 \%)$ of them suffered from fatigue. 39/105 (37\%) patients were exhibiting DAS28 disease activity (DAS28 > 2.6). All these patients suffered from fatigue, $29 / 39(74 \%)$ had severe fatigue.

Conclusion: Our results show that fatigue is a major problem in PsA with relevant impact on the health related quality of life. The relatively high percentage of patients suffering from fatigue despite clinical remission or low disease activity suggests that fatigue could be an independent outcome criterion in PsA that should be considered as an additional dimension of remission.

It seems that the clinical routine assessments of disease activity including laboratory tests and PhG do not identify fatigue in PsA sufficiently. Therefore a standardized acquisition of fatigue should be part of studies and daily routine care for PsA patients.

References:

[1] Krajewska-Włodarczyk A et al (2017): Fatigue - an underestimated symptom in psoriatic arthritis. Reumatologia. 2017; 55(3): 125-130.

[2] Chalder, T et al (1993): "Development of a fatigue scale." Journal of Psychosomatic Research. 37 (2): 147-153.

Disclosure of Interests: Catalina B. Vigener-Buxel: None declared, Hans-Eckhard Langer Shareholder of: Novartis, Roche, Merck, Sanofi-Aventis, Stephanie Gabriele Werner: None declared, René Chatelain: None declared DOI: 10.1136/annrheumdis-2020-eular.5653

\section{AB0850 CUTANEOUS LUPUS ERYTHEMATOSUS DISEASE AREA \& SEVERITY INDEX (CLASI) DEMONSTRATES THRESHOLDS FOR DETECTION OF TREATMENT RESPONSE IN A PHASE 2, PLACEBO-CONTROLLED TRIAL OF USTEKINUMAB IN SLE}

V. Werth ${ }^{1}$, B. H. Hahn ${ }^{2}$, G. Tsokos ${ }^{3}$, S. Rose ${ }^{4}$, K. Fei ${ }^{4}$, Y. I. Gregan ${ }^{4}$, R. Gordon ${ }^{4}$ K. H. Lo ${ }^{4}$, R. V. Vollenhoven ${ }^{5} .{ }^{1}$ Hospital of Univ of PA \& Veteran's Administration Med Center, PA, United States of America; ${ }^{2}$ UCLA, LA, United States of America; ${ }^{3}$ Beth Israel Hospital, MA, United States of America; ${ }^{4}$ Janssen $R \& D, L L C ., P A$, United States of America; ${ }^{5}$ Amsterdam Rheumatology and Immunology Center, Amsterdam, Netherlands
Background: In a Phase 2 study, Ustekinumab (UST) showed improvement at week (wk) 24 in the Systemic Lupus Erythematosus Disease Activity Index 2000 (SLEDAI-2K) response ( $\geq 4$-point improvement from baseline [BL]) vs placebo (PBO). ${ }^{1}$ Post hoc analysis revealed that more patients (pts) on UST vs PBO achieved $\geq 50 \%$ improvement in total CLASI activity score.

Objectives: To examine the relationships of CLASI activity responses to SLEDAI-2K (S2K) mucocutaneous disease responses.

Methods: Adults with SLE (S2K $\geq 6, \geq 1$ BILAG A and/or $\geq 2$ BILAG B scores) despite standard of care (SOC) therapy were enrolled. Pts $(n=102)$ were randomized (3:2) to UST $\sim 6 \mathrm{mg} / \mathrm{kg}$ IV or PBO at wk 0 , followed by UST $90 \mathrm{mg} \mathrm{SC}$ or PBO every 8 wks beginning at wk $8+$ SOC. S2K index measures complete improvement from BL; S2K Responder Index-50 (S2K RI-50) evaluates partial improvement $(\geq 50 \%)$ in S2K rash. CLASI rash: sum of erythema and scale/hypertrophy score. In post hoc analysis, improvement in CLASI activity score at wk 24 was calculated using increasing thresholds of $\mathrm{BL}$ disease activity and various cut points of improvement to define treatment response.

Results: Complete improvement from $\mathrm{BL}$ in rash was concordant between CLASI and S2K (correlation coefficients $[r] \geq 0.997$, Table 1 ). There was less agreement between CLASI and S2K RI-50 for assessing partial improvement in rash. Treatment difference (UST vs PBO) in \% pts achieving partial improvement in rash was observed for CLASI (60\% vs $38.5 \%)$, but not S2K RI-50 (51.1\% vs 50\%). Complete improvement from BL in mucosal ulceration was congruent between CLASI and S2K $(r=1)$. Both instruments demonstrated greater proportions of responders to UST vs PBO. Treatment differences between UST and PBO in achieving $\geq 20 \%$, $\geq 35 \%$, and $\geq 50 \%$ improvement from BL in total CLASI activity score were noteworthy at various thresholds of disease activity (Table 2).

Table 1. CLASI Activity Scores vs SLEDAI-2K Activity

\begin{tabular}{lcccc}
\hline 24-Week Improvement & Treatment & \multicolumn{2}{c}{$\begin{array}{c}\text { Activity Measure } \\
\%\left(\mathbf{n} / \mathbf{N}^{\star}\right)\end{array}$} & $\mathbf{r}^{\star \star}$ \\
& & CLASI Rash & SLEDAI-2K Rash \\
& & & \\
$100 \%$ & PBO & $30.8(8 / 26)$ & $30.8(8 / 26)$ & 1.0000 \\
& UST & $28.9(13 / 45)$ & $31.1(14 / 45)$ & 0.9997 \\
& PBO & $38.5(10 / 26)$ & $50.0(13 / 26)$ & 0.9996 \\
& UST & $60.0(27 / 45)$ & $51.1(23 / 45)$ & 0.8693 \\
& & CLASI & SLEDAl-2K & \\
$100 \%$ & & Mucosal Ulcer & Mucosal UIcer & \\
& PBO & $66.7(8 / 12)$ & $69.2(9 / 13)$ & 1.0000 \\
& UST & $89.5(17 / 19)$ & $89.5(17 / 19)$ & 1.0000
\end{tabular}

${ }^{*} \mathrm{~N}=$ Evaluated pts with BL SLEDAI rash present, total CLASI activity score $>0$, and CLAS rash or mucosal ulcer activity scores $>0$ in analyses of subcomponents; ${ }^{*}$ Calculated using tetrachoric correlation

Table 2. Differences in Partial Improvement in Total CLASI Activity Score at Various BL Disease Activity Thresholds

\begin{tabular}{lcccc}
\hline $\begin{array}{l}\text { CLASI Total Activity } \\
\text { Score }\end{array}$ & $\begin{array}{c}\text { Improvement } \\
\text { Threshold (\%) }\end{array}$ & $\begin{array}{c}\text { PBO } \\
\%\left(\mathbf{n} / \mathbf{N}^{*}\right)\end{array}$ & $\begin{array}{c}\text { UST } \\
\%\left(\mathbf{n} / \mathbf{N}^{*}\right)\end{array}$ & $\begin{array}{c}\text { Difference \% } \\
(\text { UST vs PBO) }\end{array}$ \\
\hline $\mathbf{B L}>\mathbf{0}$ & $\geq 20$ & $54.8(17 / 31)$ & $74.5(38 / 51)$ & 19.7 \\
& $\geq 35$ & $41.9(13 / 31)$ & $60.8(31 / 51)$ & 18.9 \\
$\mathrm{BL} \geq \mathbf{4}$ & $\geq 50$ & $41.9(13 / 31)$ & $54.9(28 / 51)$ & 13.0 \\
& $\geq 20$ & $58.8(10 / 17)$ & $71.9(23 / 32)$ & 13.1 \\
$\mathrm{BL} \geq \mathbf{6}$ & $\geq 35$ & $35.3(6 / 17)$ & $62.5(20 / 32)$ & 27.2 \\
& $\geq 50$ & $35.3(6 / 17)$ & $53.1(17 / 32)$ & 17.8 \\
$\mathrm{BL} \geq \mathbf{8}$ & $\geq 20$ & $53.8(7 / 13)$ & $72.0(18 / 25)$ & 18.2 \\
& $\geq 35$ & $30.8(4 / 13)$ & $60.0(15 / 25)$ & 29.2 \\
& $\geq 50$ & $30.8(4 / 13)$ & $52.0(13 / 25)$ & 21.2 \\
& $\geq 20$ & $58.3(7 / 12)$ & $70.6(12 / 17)$ & 12.3 \\
& $\geq 35$ & $33.3(4 / 12)$ & $58.8(10 / 17)$ & 25.5 \\
& $\geq 50$ & $33.3(4 / 12)$ & $47.1(8 / 17)$ & 13.8 \\
\hline
\end{tabular}

${ }^{*} \mathrm{~N}=$ Evaluated pts with $\mathrm{BL}$ total CLASI activity score $>0, \geq 4, \geq 6, \geq 8$ based on post hoc analyses

Conclusion: CLASI demonstrated partial improvement in active mucocutaneous disease that was not captured by S2K RI-50. Treatment effect favoring UST vs PBO was observed across range of thresholds of BL CLASI activity and cut points used to define improvement, which have previously been shown to be clinically meaningful. ${ }^{2}$ Findings are based on a limited sample size and treatment duration; results will be confirmed in an ongoing Phase 3 UST trial (NCT03517722).

References:

[1] Van Vollenhoven R. Lancet. 2018;392:1330

[2] Chakka S. JID. 2019;139: S101 (\#587)

Disclosure of Interests: Victoria Werth Grant/research support from: Biogen, Celgene, Gilead, Janssen, Viela, Consultant of: Biogen, Gilead, Janssen, 
Abbvie, GSK, Resolve, AstraZeneca, Amgen, Eli Lilly, EMD Serono, BMS, Viela, Kyowa Kirin, Bevra H. Hahn Grant/research support from: Janssen Research \& Development, LLC, George Tsokos Grant/research support from: Janssen Research \& Development, LLC, Shawn Rose Employee of: Janssen Research \& Development, LLC, Kaiyin Fei Employee of: Janssen Research \& Development, LLC, Y Irene Gregan Employee of: Janssen Research \& Development, LLC, Robert Gordon Employee of: Janssen Research \& Development, LLC, Kim Hung Lo Employee of: Janssen Research \& Development, LLC, Ronald van Vollenhoven Grant/research support from: AbbVie, Amgen, Arthrogen, Bristol-Myers Squibb, GlaxoSmithKline (GSK), Janssen Research \& Development, LLC, Lilly, Pfizer, Roche, and UCB, Consultant of: AbbVie, AstraZeneca, Biotest, Bristol-Myers Squibb, Celgene, Crescendo Bioscience, GSK, Janssen, Lilly, Medac, Merck, Novartis, Pfizer, Roche, UCB and Vertex, Speakers bureau: AbbVie, AstraZeneca, Biotest, Bristol-Myers Squibb, Celgene, Crescendo Bioscience, GlaxoSmithKline, Janssen, Lilly, Merck, Novartis, Pfizer, Roche, UCB, Vertex DOI: 10.1136/annrheumdis-2020-eular.4596

\section{AB0851 CAROTID ULTRASOUND IN PSORIATIC ARTHRITIS: A CASE-CONTROL STUDY}

D. Á. Galarza-Delgado', J. R. Azpiri-López², I. J. Colunga-Pedraza, D. E. Flores Alvarado ${ }^{1}$, O. Ilizaliturri Guerra ${ }^{1}$, I. C. Zárate Salinas ${ }^{2}$, P. F. Frausto Lerma ${ }^{1}$, A. Pérez Villar ${ }^{1}$, M. A. Reyes Soto ${ }^{1}$, A. C. Garza Acosta ${ }^{3} .{ }^{1}$ Hospital Universitario "Dr. José Eleuterio González", UANL, Rheumatology, Monterrey, Mexico; ${ }^{2}$ Hospital Universitario “Dr. José Eleuterio González”, UANL, Cardiology Monterrey, Mexico; ${ }^{3}$ Hospital Universitario “Dr. José Eleuterio González", UANL, Radiology, Monterrey, Mexico

Background: Patients with psoriatic arthritis ( $P s A)$ have an increased risk of cardiovascular disease (CVD). The carotid ultrasound, which measures both carotid intima-media thickness (cIMT) and carotid plaque (CP), is a non-invasive tool useful in the detection of subclinical atherosclerosis ${ }^{1}$. However, carotid ultrasound differences between PsA patients and general population have not yet been well described.

Objectives: This study aimed to compare the carotid ultrasound characteristics in PsA patients with controls.

Methods: This cross-sectional study included 70 PsA patients that fulfilled the CASPAR (Classification Criteria for Psoriatic Arthritis) criteria and 70 controls subjects matched by age and comorbidities. Patients with a history of previous atherosclerotic CVD (ischemic heart disease, cerebrovascular accident or peripheral arterial disease) and pregnancy were excluded. A clinical history and blood tests were performed. Carotid B-mode ultrasonography was used for measurements of cIMT and the presence of plaques. Increased c/MT was defined as $\geq 0.9 \mathrm{~mm}$ to $1.1 \mathrm{~mm}$. CP was defined as a focal narrowing $\geq 0.5 \mathrm{~mm}$ of the surrounding lumen or a $c / M T \geq 1.2 \mathrm{~mm}$. Descriptive analysis was done with frequencies (\%), mean ( \pm SD) and median (q25-q75), and comparisons with Chi square, Student's t and Mann-Whitney $U$ tests.

Results: A total of 138 subjects were included. Clinical and demographic characteristics are shown in Table 1. Increased cIMT and right carotid plaque were significantly more prevalent in PsA patients compared to controls $(p=0.017$ and $p=0.049$, respectively). No significant differences were found in the prevalence of carotid plaque and in the intima-media thickness between the PsA patients and the control group.

Table 1. Clinical and demographic characteristics.

\begin{tabular}{lccc}
\hline Variable & $\begin{array}{c}\text { PsA } \\
(\mathrm{n}=69)\end{array}$ & $\begin{array}{c}\text { Controls } \\
(\mathrm{n}=69)\end{array}$ & $P$ \\
\hline Age $($ mean \pm SD) & $53.58 \pm 10.946$ & $53.86 \pm 7.313$ & $\mathrm{NS}$ \\
Women, $\mathrm{n}(\%)$ & $38(55.1)$ & $59(85.5)$ & $<0.001$ \\
Obese, $\mathrm{n}(\%)$ & $26(37.7)$ & $28(40.6)$ & $\mathrm{NS}$ \\
Type 2 Diabetes, $\mathrm{n}(\%)$ & $14(20.3)$ & $9(13)$ & $\mathrm{NS}$ \\
Hypertension, $\mathrm{n}(\%)$ & $27(39.1)$ & $19(27.5)$ & $\mathrm{NS}$ \\
Dyslipidemia, $\mathrm{n}(\%)$ & $29(42)$ & $24(34.8)$ & $\mathrm{NS}$ \\
Active smoker, $\mathrm{n}(\%)$ & $15(21.7)$ & $12(17.4)$ & $\mathrm{NS}$ \\
Disease duration, median (q25-q75) & $5(2.5-8)$ & - & - \\
Methotrexate, $\mathrm{n}(\%)$ & $46(66.7)$ & - & - \\
Biologics, $\mathrm{n}(\%)$ & $23(33.3)$ & - & - \\
DAS28-ESR, (mean \pm SD) & $3.74 \pm 1.477$ & - & - \\
DAS28-CRP, (mean \pm SD) & $2.43 \pm 1.088$ & - & - \\
DAPSA, median $(\mathrm{q} 25-\mathrm{q} 75)$ & $35(27.5-58.5)$ & - & - \\
& & &
\end{tabular}

Conclusion: Patients with psoriatic arthritis have a higher cardiovascular risk, as proven by the increased cIMT found on carotid ultrasound results. Therefore, it is advisable to perform a carotid ultrasound in patients with PsA to achieve an optimal management of the disease. The rheumatologist must be aware of the importance of performing a complete cardiovascular evaluation to provide a correct treatment in order to lower possible cardiac events.

\section{References:}

[1] Lucke, M., Messner, W., Kim, E.S.H. et al. The impact of identifying carotid plaque on addressing cardiovascular risk in psoriatic arthritis. Arthritis Research \& Therapy 18, 178 (2016). https://doi.org/10.1186/ s13075-016-1074-2

Table 2. Carotid ultrasound findings.

\begin{tabular}{lccc}
\hline Variable & PsA (n=69) & Controls $(\mathrm{n}=69)$ & $P$ \\
\hline Any carotid plaque, $\mathrm{n}(\%)$ & $27(39.1)$ & $17(24.6)$ & $\mathrm{NS}$ \\
Right carotid plaque, $\mathrm{n}(\%)$ & $18(26.1)$ & $8(11.6)$ & $\mathbf{0 . 0 4 9}$ \\
Left carotid plaque, $\mathrm{n}(\%)$ & $19(27.5)$ & $15(21.7)$ & $\mathrm{NS}$ \\
Increased cIMT, $\mathrm{n}(\%)$ & $9(13)$ & $1(1.4)$ & $\mathbf{0 . 0 1 7}$ \\
Right cIMT, median (q25-q75) & $0.58(0.46-0.76)$ & $0.6(0.51-0.69)$ & $\mathrm{NS}$ \\
Left cIMT, median (q25-q75) & $0.58(0.5-0.73)$ & $0.61(0.54-0.78)$ & $\mathrm{NS}$ \\
\hline
\end{tabular}

Disclosure of Interests: None declared

DOI: 10.1136/annrheumdis-2020-eular.5228

\section{AB0852 LONG TERM FOLLOW UP OF VISCOSUPPLEMENTATION WITH DIFFERENT TYPES OF INTRA-ARTICULAR HYALURONIC ACID IN OSTEOARTHRITIS OF THE KNEES}

A. K. Aggarwal ${ }^{1}$, N. Aggarwal ${ }^{1}$, D. Jain ${ }^{1} .{ }^{1}$ Institute of Rheumatology and Pain, Brij Medical Centre, Rheumatology \& Pain, Ghaziabad, India

Background: Knee osteoarthritis $(\mathrm{OA})$ is a progressive degenerative condition resulting in functional loss besides pain and discomfort.[1] The aim of treatment as of today should be joint preservation in order to prevent surgery, alleviation of symptoms and improvement of functions.

Viscosupplementation (VES) with Intra-articular hyaluronic acid (IAHA) injections has been shown to have protective physiochemical functions and may confer disease-modifying, long term effects on the articular cartilage. [2][3] However conflicting guidelines, availability of multiple varieties, and absence of good studies or any treatment protocol has resulted in lack of confidence of the results of IAHA.

Objectives: To determine the Long term effectiveness of VES with various types IAHA in OA in maintaining functional improvement of the knees and evaluate the duration of effect of first and repeat injections of VES.

Methods: From the 15 year retrospective longitudinal study of data of VES with different types of IAHA in our Centre, we evaluated the following outcomes:

1. The WOMAC scores were regularly done on each visit of the study group. Those with maintained improvement in the WOMAC total score were followed and reinjected when the scores started decreasing.

2. All patients who were given Non Animal Source Hyaluronic acid (NASHA) were included in the study. Patients with repeat IAHA were further evaluated for Type of NASHA used and were categorized into 2 groups accordingly:

a. Those with High Molecular weight Hyaluronic acid (HMW-HA) 6-8mg/ml $-6 \mathrm{ml}$ single injections

b. Those with Very High Molecular weight, Cross linked Hyaluronic acid (VHMW-HA) 20- $\mathrm{mg} / \mathrm{ml}-3 \mathrm{ml}$ injections.

Results: The total number of patients treated over the last 15 years was 1206 with 689 having Kellgren and Lawrence (KL) Grade III OA, and 517 KL Grade IV OA. The data showing distribution of type of IAHA used in the group, the average Gap between the injections with the Range in years for the least gap and the longest gap between the injections, along with the follow up to giving the 3ro injection was given is summarized in Chart 1: Time gap between repeat IAHL injections in OA knees.

Chart 1. Time gap between repeat IAHL injections in OA knees

\begin{tabular}{lcclllllrc}
\hline OA GRADE \& & I INJ & \multicolumn{3}{c}{ II INJ } & \multicolumn{3}{c}{ III INJ } \\
\hline VISCOUS TYPE & $\mathrm{N}=1206$ & Gap 1 & $\begin{array}{l}\text { Range } \\
\text { KL GRADE III OA }\end{array}$ & $\mathrm{N}=689$ & & $\mathrm{~N}=482$ & Gap 2 & Range & $\mathrm{N}=578$ \\
Group A:HMW-HA & 237 & 0.92 & $0.8-1.6$ & 144 & 0.87 & $0.6-1.1$ & 105 \\
Group B:VHMW-HA & 452 & 2.54 & $1.8-3.4$ & 298 & 2.43 & $1.7-2.8$ & 209 \\
KL GRADE IV OA & $\mathrm{N}=517$ & & $\mathrm{~N}=340$ & & & $\mathrm{~N}=340$ & \\
Group A:HMW-HA & 154 & 1.02 & $0.6-1.2$ & 96 & 0.95 & $0.5-1.1$ & 75 \\
Group B:VHMW-HA & 363 & 2.01 & $1.4-2.3$ & 244 & 1.89 & $1.4-2.2$ & 189
\end{tabular}

Gap 1 - Average Time between I \& II inj.in years, Gap 2 - Average Time between II \& III inj. in years

Range - Being the time in years for the least \& the longest Gap between the injections HMW-HA - High Molecular weight Hyaluronic acid

VHMW-HA - Very High Molecular weight, Cross linked Hyaluronic acid 